\title{
Considerações Sobre o Uso de Mapas na Web Para o Ensino de Ciência do Solo
}

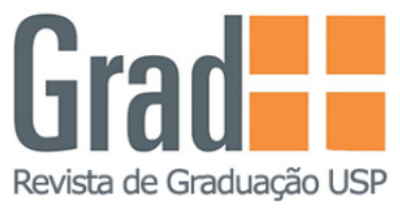

\author{
Pedro Henrique Freire Janzantti, Déborah de Oliveira \\ Departamento de Geografia da Faculdade de Filosofia, Letras e Ciências Humanas da Universidade de São Paulo
}

*Autores para correspondência: pedro.henrique.janzantti@usp.br; debolive@usp.br

\begin{abstract}
RESUMO
O presente artigo apresenta reflexões sobre as possibilidades da adoção de ferramentas cartográficas como método de ensino para Pedologia, no âmbito das Tecnologias da Informação e Comunicação (TICs). Baseado no conceito de interatividade e flexibilidade, o website de mapas do Instituto Brasileiro de Geografia e Estatística (IBGE) foi analisado. As ementas de diferentes cursos referentes à Ciência do Solo corroboraram a análise da viabilidade do uso das TICs como recurso de pesquisa e ensino. $\mathrm{O}$ sentido de interatividade e o de flexibilidade foram questionados tendo em vista que o website é apenas um visualizador. Finalmente, concluímos que as TICs devem ser adotadas quando cabem na realidade específica da sala de aula, e que o incentivo ao uso de tecnologia na educação deve partir do ensino superior.
\end{abstract}

Palavras-Chave: Mapas na Web; Educação; Cartografia; Pedologia.

\begin{abstract}
The article presents reflections on the possibilities of Pedology education by adopting cartographic tools as method of teaching, named Information and Communication Technology (ICT). Based on interactivity and flexibility, we analyzed the Maps website from the Brazilian Institute of Geography and Statistics (IBGE). Syllabus from different Soil Sciences courses supported the viability analysis on using ICT as a resource to research and education. The meaning of interactivity and flexibility were questioned based on the fact this website only allows visualization. Finally, we concluded that ICTs shall be used when it suits specific classrooms, and the stimulus to educational technology usage should arise from higher education.
\end{abstract}

Keywords: Maps on the Web; Education; Cartography; Pedology.

\section{Introdução}

O solo, objeto de estudo da Pedologia, pode ser definido como a(s) camada(s) de material mineral e/ou orgânico, geralmente solta(s), afetada(s) por processos físicos, químicos e/ou biológicos na/ou próxima à superfície planetária que, comumente, apresenta líquidos, gases e biota (VAN ES, 2017).

A natureza multidisciplinar envolvida na caracterização do solo é um grande obstáculo à assimilação desse conteúdo. Assim, o contato com o material orgânico e mineral, bem como a percepção da localização de diferentes tipos de solos podem ser estratégias facilitadoras para o entendimento da cartografia de solos.

Nesse sentido, é preciso constituir meios efetivos de comunicação para o ensino de Pedologia
(SOUSA \& MATOS, 2012), de forma a demonstrar a relação do solo com outros elementos. Um caminho para essa abordagem pode ser o uso de Tecnologias de Informação e Comunicação (TICs), definidas por Miranda (2007) como a conjugação da tecnologia computacional com a tecnologia das telecomunicações, e que tem na internet o seu mais forte meio.

Diferentes autores abordaram a viabilidade do uso de geotecnologias no ensino de Geografia e Educação Ambiental, na educação formal e não formal (SANTOS, 2017; SILVA \& CARNEIRO, 2012; JANZANTTI et al., 2017a, 2017b; GONÇALVES et al., 2007; BUENO \& COLAVITE, 2012; ALBUQUERQUE et al., 2012). Todavia, podemos nos perguntar: Esse tipo de recurso 
serve apenas como ilustração ou como estrutura para o planejamento de aulas sobre o assunto? O recurso utilizado é concebido como uma ferramenta única ou são exploradas as tecnologias que nela se associam (Sistema de Informação Geográfica, Sistema de Navegação por Satélite, Sensoriamento Remoto etc.)?

Os mapas na web são um exemplo de forma de representação cartográfica decorrente do desenvolvimento das TICs. Em específico, o presente artigo discutirá um tipo de mapa presente na web, os denominados "Mapas Interativos", do Instituto Brasileiro de Geografia e Estatística (IBGE). Além de ter acesso gratuito, o site reúne mapas temáticos e tem seu sistema associado a imagens de satélite (Digital Earth), podendo ser visto como ferramenta didática graças à interatividade que proporciona a sua popularização. Nosso objetivo é fazer uma avaliação preliminar da viabilidade da utilização desse mapa no ensino de Pedologia em nível superior.

\section{Métodos}

Exploramos a relação entre os diferentes elementos do sistema terrestre tendo como concepção de Pedologia a definição apresentada por Queiroz Neto (1984) e Ross (1995):

Pedologia é o discurso do solo. Este apresenta características próprias através de certas ações que envolvem outros elementos da paisagem. O estudo dessa disciplina envolve sua caracterização (Pedologia Descritiva) e o entendimento dos processos de gênese (Pedologia Evolutiva). (QUEIROZ NETO, 1984).

A Pedologia deve se preocupar com a caracterização morfológica, física, química e mineralógica dos solos ao mesmo tempo que executa o mapeamento e a classificação dos tipos de solo. Os estudos de solos devem atender dois objetivos - o de avaliar a aptidão ou a capacidade agropecuária do uso das terras e subsidiar, com informações das características texturais, estruturais e químicas, a análise da dinâmica do relevo, da fragilidade e da funcionalidade dos sistemas ambientais onde cada tipo dominante de solo ocorre (ROSS, 1995).

Ambas as definições mostram preocupação tanto com o objeto de estudo, como com seu método, o entendimento da descrição e dos mecanismos de gênese, além da atenção para a utilidade desses estudos. Assim, compreender o contexto do solo é bastante importante, e a paisagem é um conceito-chave. Isso porque ela fornece pistas visuais à associação entre os usos da terra e os diversos fatores de formação dos solos.

Por essa razão, escolheu-se como recurso para abordar a Pedologia e seu conteúdo o mapa na web associado ao Digital Earth (semelhante ao Google Earth e a outros sistemas). Essa integração da Cartografia Temática (e, consequentemente, de Sistemas de Informação Geográfica - SIGs) em um ambiente com imagens de Sensoriamento Remoto permite a exploração da paisagem e de novos conteúdos a partir de uma nova experiência (QUEIROZ FILHO, 2005, p. 170).

Utilizamos como materiais: 1) O website dos mapas interativos do IBGE (disponível em: http:// mapasinterativos.ibge.gov.br/sigibge); 2) Ementas de cursos de Pedologia de diferentes universidades públicas. O primeiro foi o objeto desse estudo, que, associado ao Base Map, constitui uma TIC com potencial à educação. O Base Map é um tipo de serviço web de dados geoespaciais que dão aparência estética ao fundo do mapa. Já o segundo, as ementas, serviu à elaboração de uma tabela com informações referentes a diferentes cursos de Ciência do Solo.

O objetivo dessa etapa foi entender as ênfases e o grau de multidisciplinaridade envolvido, para assim avaliarmos as possíveis relações dos conteúdos abordados com os dados disponíveis nesse mapa na web. Dessa forma, esperávamos avaliar a viabilidade de adoção da presente proposta.

Conforme Freire et al. (1998) discutem, o computador é uma ferramenta que amplifica, acrescenta, modifica, transforma e representa um determinado conteúdo ou conceito de outra maneira. É importante avaliar os recursos 
focalizando as possibilidades que criam; para isso é necessário considerar suas características, tais como interface e conteúdo. Assim sendo, destacam as autoras que discriminar as situações possíveis de utilização implica analisar o conteúdo programático à luz das possibilidades oferecidas pela tecnologia que se deseja empregar.

Esse estudo, portanto, seguiu os procedimentos ilustrados na Figura 1.

\section{Resultados e Discussão}

\section{As Ementas}

Foram selecionadas algumas universidades públicas brasileiras localizadas em diferentes regiões político-administrativas para ilustrar o panorama da diversidade de ementas das disciplinas de Pedologia. Em primeiro lugar, constatamos a dificuldade de encontrar sistemas organizados e com informações completas. A Tabela 1 foi preenchida com o nome dessas universidades, o nome da disciplina, a carga horária $(\mathrm{CH})$ e o conteúdo programático.

Com base na Tabela 1 , vemos que há, por exemplo, um curso de Geografia que não possui disciplina referente ao ensino exclusivo de Pedologia (UFMT, 2009). No caso da Universidade Federal do Mato Grosso, o conteúdo dessa ciência está inserido no curso de Geomorfologia. Isso pode ser interpretado como um equívoco, visto que, embora haja relação entre os objetos da Pedologia e da Geomorfologia (solo e relevo, respectivamente), suas bases conceituais são diferentes, bem como seus métodos de estudo (QUEIROZ NETO, 2000).

Também se observa que a carga horária das disciplinas que abordam Pedologia varia muito. De acordo com a Tabela 1, nas universidades analisadas a carga horária varia de 60 a 180 horas, que são divididas entre atividades práticas e teóricas. No caso dos cursos com cargas horárias reduzidas, a inserção de atividades diferenciadas em sala de aula fica dificultada.

Por outro lado, o conteúdo programático do estudo de Pedologia geralmente está associado à temática ambiental, e inclui um tópico referente à classificação dos solos (taxonomia). Considerando esse aspecto, a inserção dos mapas interativos do IBGE pode ser produtiva, por se articular não só a esse, mas também a outros tópicos previstos nas ementas.

\section{Os Mapas e a Multidisciplinaridade}

$\mathrm{O}$ website do IBGE tem como objetivo a divulgação de informação em ambiente mais convidativo,

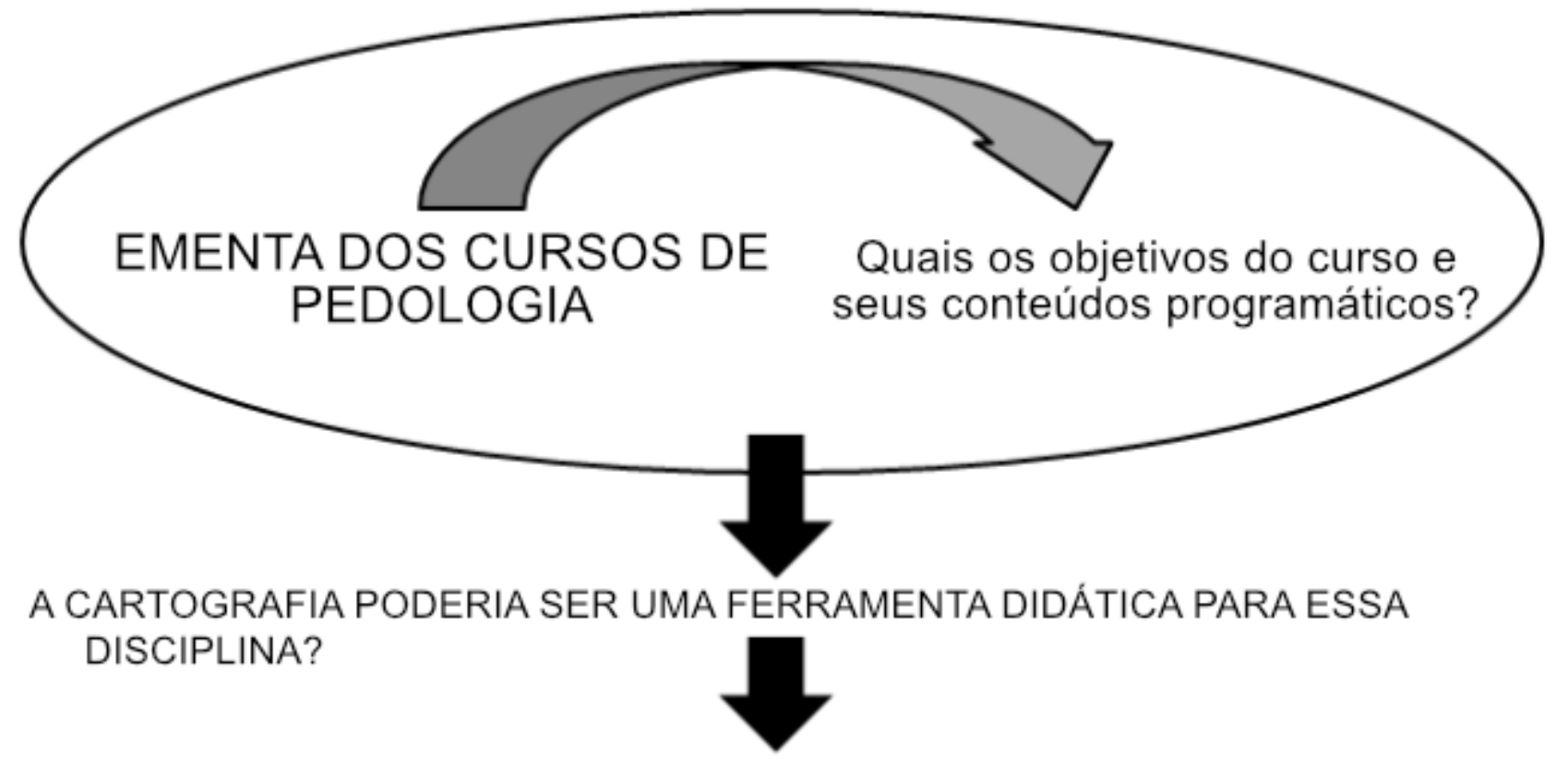

\section{Qual a viabilidade do uso desses sites?}

Figura 1 - Procedimentos adotados no estudo. Fonte: elaborado pelos autores, 2017, baseado em Freire et al. (1998). 


\begin{tabular}{|c|c|c|c|}
\hline FACULDADE & $\begin{array}{l}\text { NOME DA } \\
\text { DISCIPLINA }\end{array}$ & $\mathrm{CH}$ & CONTEÚDO PROGRAMÁTICO \\
\hline $\begin{array}{l}\text { UFGRS - } \\
\text { Universidade } \\
\text { Federal do Rio } \\
\text { Grande do Sul }\end{array}$ & $\begin{array}{l}\text { Introdução à } \\
\text { Pedologia e à } \\
\text { Ecogeografia }\end{array}$ & $75 h$ & $\begin{array}{l}\text { - A geografia e os solos; } \\
\text { - Intemperismo e formação do solo. Pedosfera e biosfera: inte- } \\
\text { rações clima-solo-água-organismos; } \\
\text { - Propriedades dos solos. Ecorregiões terrestres e solos do } \\
\text { mundo; } \\
\text { - Solos do Brasil. Uso da terra e conservação da paisagem; } \\
\text { - Técnicas de levantamento e mapeamento pedológico; } \\
\text { - Práticas de observação pedológica em campo. }\end{array}$ \\
\hline $\begin{array}{l}\text { UFPR - } \\
\text { Universidade } \\
\text { Federal do } \\
\text { Paraná }\end{array}$ & Pedologia & $60 \mathrm{~h}$ & $\begin{array}{l}\text { - Conceito e evolução dos solos e evolução da Pedologia; } \\
\text { - Fatores de formação do solo e processos pedogenéticos; } \\
\text { - O perfil do solo: nomenclatura dos horizontes; } \\
\text { - Características do perfil do solo (físicas, químicas e mineralógicas); } \\
\text { - Características morfológicas; } \\
\text { - Sistema Brasileiro de Classificação dos Solos; } \\
\text { - Capacidade de uso, ocupação e erosão dos solos. }\end{array}$ \\
\hline $\begin{array}{l}\text { USP - } \\
\text { Universidade de } \\
\text { São Paulo }\end{array}$ & Pedologia & $180 \mathrm{~h}$ & $\begin{array}{l}\text { - As várias abordagens conceituais de solos e Pedologia; } \\
\text { - Os constituintes dos solos: sólidos (minerais e orgânicos), } \\
\text { líquidos e gasosos; } \\
\text { - Fundamentos de gênese dos solos: fatores de formação e seus } \\
\text { agentes; } \\
\text { - Morfologia dos solos: a macro e a micromorfologia; } \\
\text { - Distribuição dos solos em diferentes escalas: da zonalidade } \\
\text { dos processos pedogeoquímicos aos mecanismos particulariza- } \\
\text { dos das vertentes; } \\
\text { - Procedimentos para o estudo e pesquisa dos solos em dife- } \\
\text { rentes escalas de abordagem; } \\
\text { - Problemas gerais da classificação dos solos; } \\
\text { - Aplicaçães científicas e utilitárias do estudo dos solos; } \\
\text { - A educação em solos e suas formas de divulgação e populari- } \\
\text { zação; } \\
\text { - Ensino de solos para a educação básica. }\end{array}$ \\
\hline $\begin{array}{l}\text { UFPE - } \\
\text { Universidade } \\
\text { Federal de } \\
\text { Pernambuco }\end{array}$ & Pedologia & $60 \mathrm{~h}$ & $\begin{array}{l}\text { - A ciência do solo e sua importância para a geografia; } \\
\text { - Gênese do solo: aspectos gerais. Composição e principais } \\
\text { propriedades do solo; } \\
\text { - Classificação e geografia dos solos. }\end{array}$ \\
\hline $\begin{array}{l}\text { UFMT - } \\
\text { Universidade } \\
\text { Federal do } \\
\text { Mato Grosso }\end{array}$ & $\begin{array}{l}\text { Fundamentos } \\
\text { de Geomorfo- } \\
\text { logia }\end{array}$ & $60 \mathrm{~h}$ & $\begin{array}{l}\text { - Estudar, conhecer e reconhecer a Terra: Os ecossistemas. Os } \\
\text { minerais. Os processos endógenos e exógenos. As alterações } \\
\text { nas rochas. Os recursos naturais: Os climas. Os solos. As rochas. } \\
\text { O relevo. A hidrografia e a cobertura vegetal; } \\
\text { - Identificar os processos externos e seus efeitos, tais como a } \\
\text { ação geológica da água, do vento, do gelo; } \\
\text { - Estudar os processos internos e seus efeitos (Geotectônica) e } \\
\text { os aspectos da Geologia e da Geomorfologia do Brasil; } \\
\text { - Conhecer os recursos energéticos (carvão, petróleo, xisto betumi- } \\
\text { noso, energia geotérmica, urânio e energia nuclear. }\end{array}$ \\
\hline
\end{tabular}

Tabela 1 - Compilação de ementas de cursos relacionados à Pedologia de universidades públicas de diferentes regiões do Brasil. Fonte: elaborado pelos autores, 2017, baseado nas ementas dos cursos, disponíveis on-line. 
não necessariamente para fins científicos. São apresentados, assim, dez temas relacionados à temática físico-ambiental do Brasil. Essas camadas são: biomas, climas, fauna ameaçada, geologia, potencial agrícola, regiões hidrográficas, relevo, solos, uso da terra e vegetação (Figura 2).

Essas camadas são úteis para a discussão de alguns dos fatores que atuam na formação do solo: material de origem, relevo, clima, organismos e tempo. A sobreposição das camadas clima, geologia e relevo permite compreender a interdependência desses elementos dentro da natureza do sistema terrestre.

A camada uso da terra, relativa à cartografia das formas de apropriação dos recursos para fins econômicos, introduz o homem também como agente e permite discutir seu papel. Por exemplo, os usos agrícolas apresentados nessa cartografia são adequados ao clima, ao relevo e aos solos da localização?

Diferentemente de Mendonça et al. (2009), não acreditamos que, com a internet e os conceitos de visualização de dados geoespaciais, os objetos de estudo da cartografia continuem os mesmos; entendemos que esses mapas na web integrados a imagens de satélite (Digital Earth) superam as características rígidas da cartografia analógica e propiciam uma nova experiência.

\section{A Nova Experiência: Interatividade e Multies- calaridade}

Podemos chamar de interatividade a possibilidade de integração de camadas que permite, além da análise do fenômeno, uma visão sistêmica que relaciona outros temas e a paisagem (como reflexo da história da sociedade como um todo). A paisagem, vista através das diferentes formas de visualização, pode ser bastante interessante. Entretanto, é necessário cuidado, uma vez que o meio pode se tornar mais importante que a própria representação cartográfica (QUEIROZ FILHO \& GIANNOTTI, 2012). Em outras palavras, corre-se o risco de os usuários direcionarem toda a atenção ao recurso tecnológico e se dispersarem em relação ao conteúdo envolvido (JANZANTTI et al., 2017a), daí a importância da orientação do professor nesse processo.

Embora a interatividade propiciada pelo recurso dê ao aluno uma sensação de participação da cena, é preciso compreender que a habilitação de camadas e a alteração das perspectivas de visualização não constituem, necessariamente, produção de conhecimento (JANZANTTI et al., 2017b). Além disso, vale lembrar que nenhuma TIC substitui a figura do professor, que continua a ser o mediador, preparando o aluno para a contextualização dos conteúdos estudados (FREIRE et al., 1998; SANTOS, 2017).

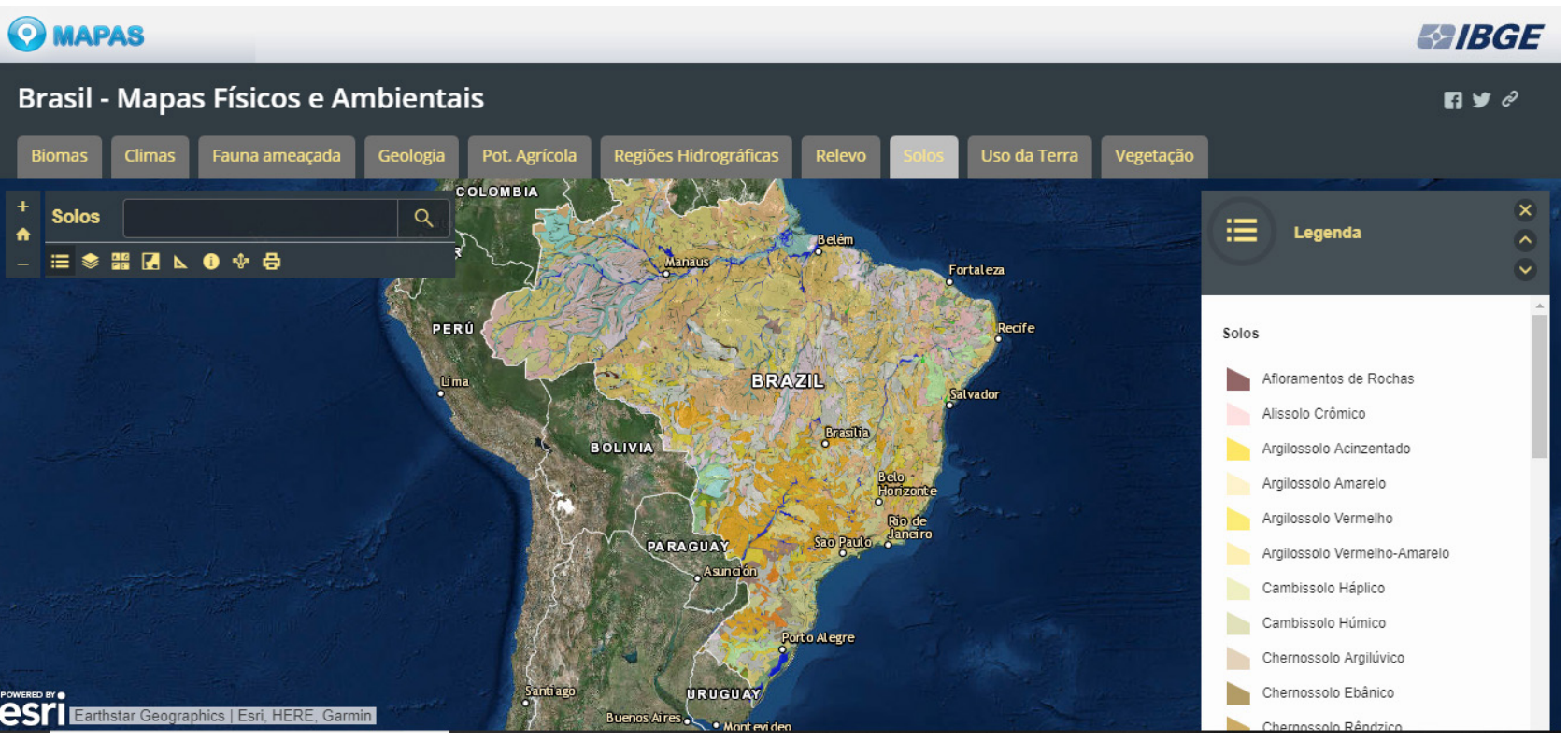

Figura 2 - Mapas interativos do IBGE. Fonte: mapas interativos do IBGE. Disponível em: >http://mapasinterativos.ibge. gov.br/sigibge/>. Acessado em 10 jan. 2017. 
A opção de alterar o enquadramento é decorrente da possibilidade de visualização dos fenômenos em diferentes níveis escalares (multiescalaridade). Nesse website não é um recurso muito explorado por questões de limitações técnicas. Conforme a Figura 3 apresenta, dado um determinado zoom, a camada da cartografia temática desaparece e indica a inexistência de legenda.

Embora haja essa limitação, o website apresenta a taxonomia brasileira como multicategórica e baseada em hierarquia de grupos (JACOMINE,
2009). A taxonomia do solo é um sistema de classificação de solo que considera seus diferentes atributos morfogenéticos. Conforme a Figura 4 mostra, ao clicar sobre um trecho do mapa, obtemos uma descrição taxonômica do solo, do Sistema de Classificação Brasileira de Solos. Nesse caso, o mapa permite visualizar até o terceiro nível (dos grandes grupos), o que faz esse recurso bastante útil para a discussão sobre os esquemas de organização pedológica e os sistemas de classificação.

MAPAS

6) IBGE

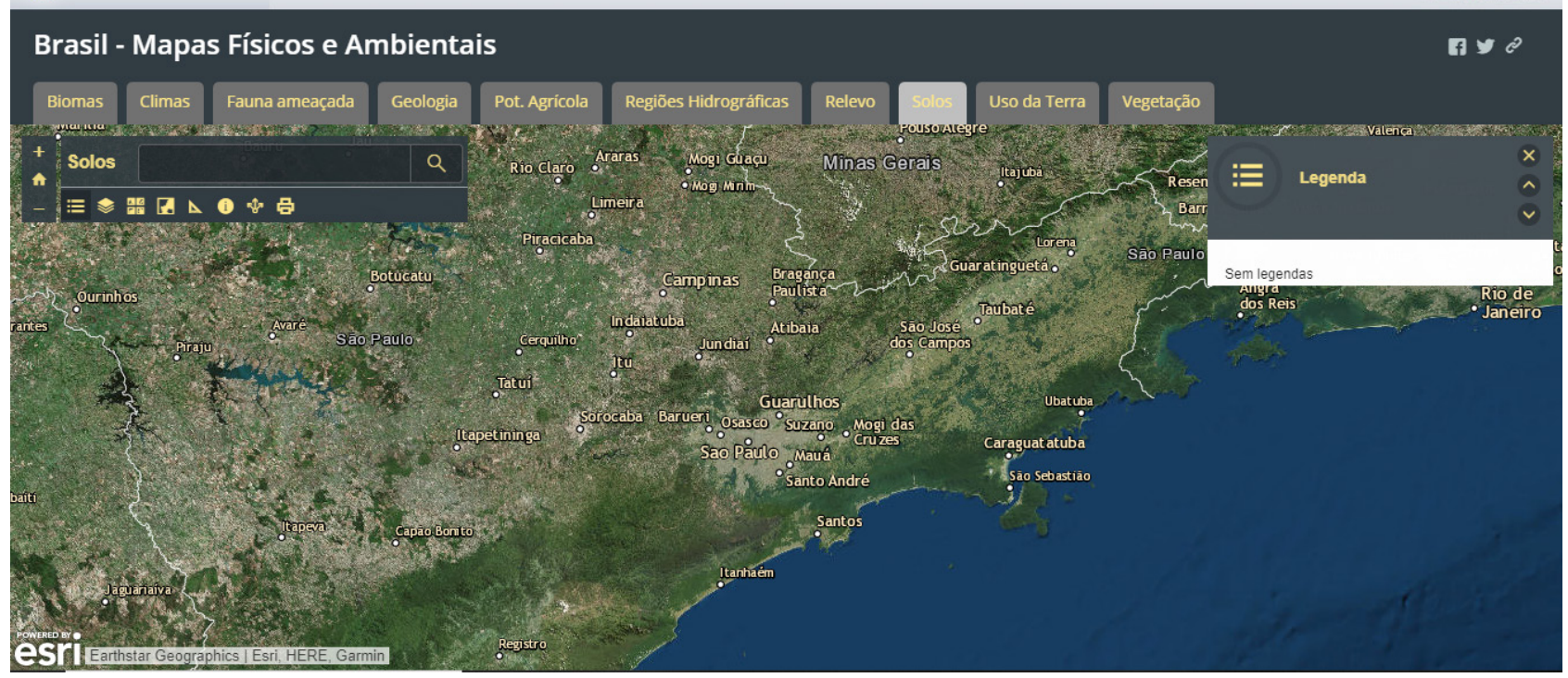

Figura 3 - A partir de uma escala, as classes desaparecem e não há legenda vinculada. Fonte: mapas interativos do IBGE. Disponível em: \http://mapasinterativos.ibge.gov.br/sigibge/>. Acessado em 10 jan. 2017.

MAPAS

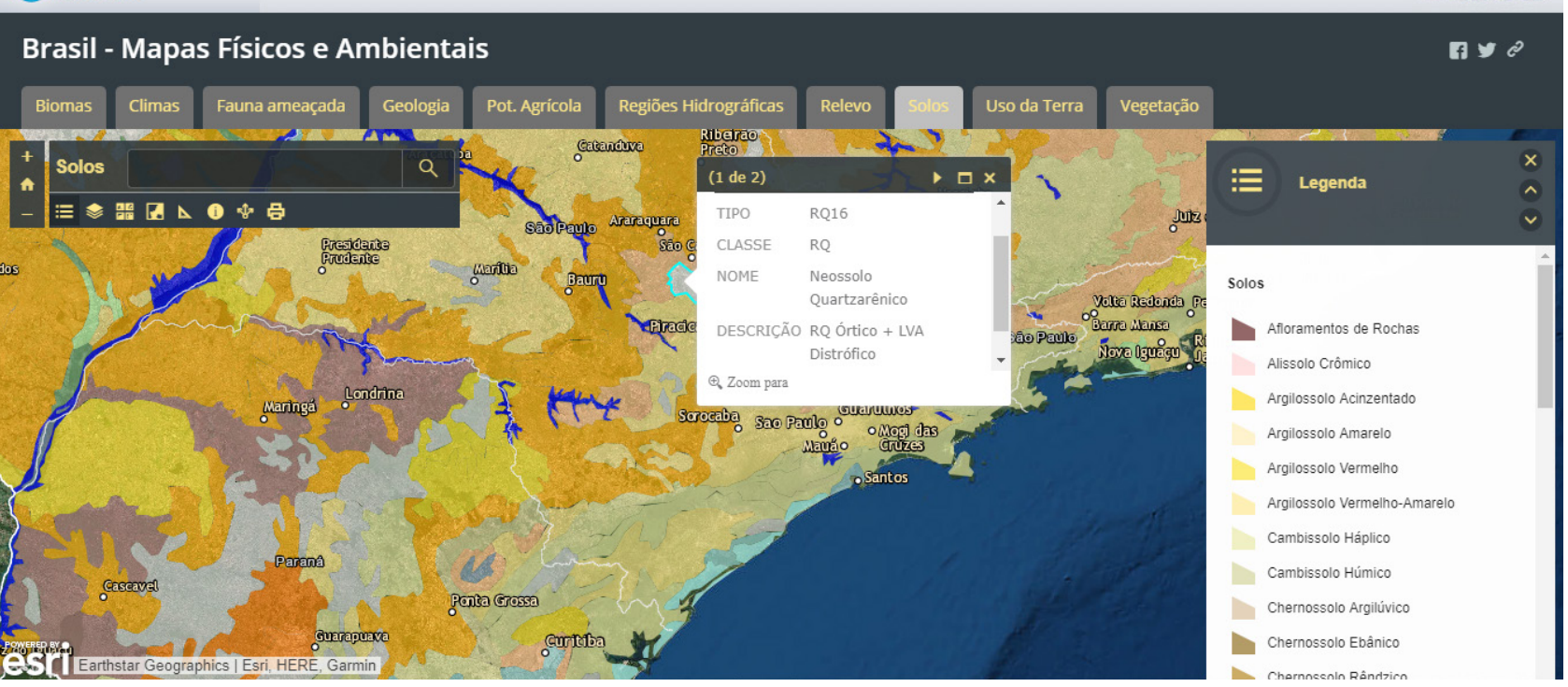

Figura 4 - Apresenta-se uma janela com o grupo, subgrupo e o grande grupo para cada feição da cartografia. Fonte: mapas Interativos do IBGE. Disponível em: 〈http://mapasinterativos.ibge.gov.br/sigibge/>. Acessado em 10 jan. 2017. 


\section{Flexibilidade ou Inflexibilidade?}

A flexibilidade dos mapas da web, e dessa ferramenta em específico, ocorre por envolver diferentes conteúdos. Entretanto, o mapa em si torna-se um instante de visualização de dados geográficos (QUEIROZ FILHO \& GIANNOTTI, 2012). Além disso, o potencial dessa ferramenta fica estancado ao se apresentar apenas uma cartografia para cada tema, sendo que, internamente, cada área do conhecimento inclui debates teóricos sobre representações cartográficas.

Outra questão é que os mapas integrados nessa plataforma não foram elaborados pelo próprio IBGE, isto é, esse website serve para alocar mapas produzidos por diferentes fontes que utilizam diversas metodologias. O mapa de solos, por exemplo, conforme a aba Informações descreve, "identifica e cartografa os diferentes tipos de solos do Brasil utilizando a nomenclatura e as especificações recomendadas pelo Sistema Brasileiro de Classificação de Solos - SBCS da Embrapa (1999)".

Embora haja informação referente à metodologia utilizada para à produção do mapa, seria desejável que existissem outras referências e explicações em relação a sua elaboração. No caso da Pedologia, por exemplo, além da cartografia do Sistema Brasileiro de Classificação dos Solos (apresentado no website), existem classificações elaboradas pelo Departamento de Agricultura dos Estados Unidos e pela Organização das Nações Unidas para a Alimentação e a Agricultura (FAO).

Da forma em que está inserido na internet, esse website pode servir como fonte de informação, mas não necessariamente contribui para os debates e para a apreensão da tecnologia. Daí também a necessidade de se discutirem seu processo de elaboração e as técnicas ali associadas.

Seria, assim, importante discutir elementos de cartografia sistemática, como os sistemas de projeções cartográficas, a escala e as coordenadas, e de cartografia temática, como as variáveis qualitativas, quantitativas e os tipos de variáveis visuais (ARCHELA, 1999). Nesse sentido, seria proveitoso acrescentar cartografias de variáveis quantitativas, como, por exemplo, mapas de índices pluviométricos que têm relação com o clima, e, consequentemente, com a pedogênese.

\section{Considerações Finais}

Encontrar materiais complementares para o ensino de Pedologia não é tão simples. Conforme constata Oliveira (2014), o solo não é tão valorizado nos estudos de educação ambiental, como são o ar, a água, os seres vivos e as rochas. Essa valorização do campo disciplinar da Pedologia deve começar na formação dos professores.

Embora se acredite que o uso de geotecnologias em sala de aula torne o ensino mais dinâmico e interativo, acompanhando a tendência do mundo moderno (SANTOS, 2017; ALBUQUERQUE et al., 2012), consideramos mais interessante introduzir novas ferramentas de acordo com cada realidade específica do ambiente educacional.

Por essa razão, buscamos avaliar os mapas interativos do IBGE tendo como referência as necessidades da disciplina apresentadas pelas ementas de cinco universidades. A escolha de novas ferramentas não decorre apenas de uma demanda de atualização tecnológica por si só, mas deve ser orientada pelas necessidades pedagógicas requeridas pelo conteúdo e desejadas pelo professor (FREIRE et al., 1998).

Inserir novos recursos não significa substituir os antigos, como os trabalhos de campo ou as experiências em sala de aula. Significa, sim, explorar outras possibilidades complementares. Portanto, reconhecemos a necessidade de avaliações cuidadosas das TICs para sua inserção em sala de aula, pois estas devem ser aliadas do processo de aprendizagem ao invés de representar empecilhos.

Como Queiroz Filho (2006), apesar das críticas ao sentido da interatividade (e, por consequência, da característica multiescalar), julgamos importante garantir que não se tenha comprometido a disseminação das informações espaciais. Consideramos que futuramente avaliações quantitativas e relatos de experiências serão relevantes para analisar a interação humano-computador dos alunos e dos docentes com essa TIC. 
Para fins didáticos, os mapas interativos do IBGE apresentam grande potencial para servir de subsídio a novas discussões. Dessa forma, o presente estudo buscou oferecer auxílio àqueles professores que consideram a possibilidade de inserção de novos recursos em sala de aula.

\section{Referências Bibliográficas}

ALBUQUERQUE, E. L. S.; MEDEIROS, C. N.; GOMES, D. D. M. \& CRUZ, M. L. B. "Sig-Web Ceará em Mapas Interativos, Novas Ferramentas na Cartografia Escolar". Mercator, vol. 11, n. 24, 2012, pp. 253-269.

ARCHELA, R. S. "Imagem e Representação Gráfica". Geografia (Londrina), vol. 8, n. 1, 1999, pp. 5-11.

BUENO, R. H. \& COLAVITE, A. P. "Uso das Imagens de Satélite do Google Earth na Análise Urbana: uma Proposta para o Ensino de Geografia". Revista de Geografia, Meio Ambiente e Ensino, vol. 2, n. 1, 2012, pp. 217-229.

FREIRE, F.M.P.;PRADO, M.E.B.B, MARTINS, M. C. \& SIDERICOUDES, O. "A Implantação da Informática no Espaço Escolar: Questões Emergentes ao Longo do Processo". Revista Brasileira de Informática na Educaşão, n. 3, 1998, pp. 45-62.

GONÇALVES, A. R.; ANDRÉ, I. R. N.; AZEVEDO, T. S. \& GAMA, V. Z. "Analisando o Uso de Imagens do "Google Earth" e de Mapas no Ensino de Geografia”.Ar@me-Revista Electrónica de Recursos en Internet sobre Geografia y Ciencias Sociales, n. 97, 2007, p. 97.

JACOMINE, P. K. T. "A Nova Classificação Brasileira de Solos". Anais da Academia Pernambucana de Ciência Agronômica, vol. 5, 2009, pp. 161-179.

JANZANTTI, P. H. F.; MOREIRA, C. M.; MENDONÇA, C. A.; CAVALCANTE, F. L. \& BICUDO, T. G. "O Uso do Google Earth na Educação Ambiental: Áreas Contaminadas". XVIII Simpósio Brasileiro de Sensoriamento Remoto, 2017, Santos. Anais do XVIII Simpósio Brasileiro de Sensoriamento Remoto - SBSR, 2017a, pp. 1114-1120.

"How to Talk about Contaminated Land in Scientific Dissemination Events?". Revista Cultura e Extensão USP, vol. 16, 2017b, pp. 80-93.

MENDONÇA, A. L. A. de; SCHMIDT, M. A. R. \& DELAZARI, L. S. "Publicação de Mapas na Web: Abordagem Cartográfica com Uso de Tecnologias Código-Aberto". Boletim de Ciências Geodésicas, vol. 15, n. 1, 2009.

MIRANDA, G. L. "Limites e Possibilidades das TIC na Educação". Sísifo. Revista de Ciências da Educação, vol. 3, 2007, pp. 41-50.
OLIVEIRA, Déborah de. "O Conceito de Solo sob o Olhar de Crianças do Ensino Fundamental em Escolas de São Paulo-SP". Ciência e Natura, vol. 36, 2014, pp. 210-214.

QUEIROZ FILHO, A. P. de. "Considerações sobre a Interatividade na Cartografia". Terra Livre, vol. 2, n. 27, 2006, pp. 165-184.

- O Voo Virtual: Metáfora e Representacãa Cartográfica Tridimensional. Tese (Doutorado em Engenharia de Transportes), Escola Politécnica, Universidade de São Paulo, São Paulo, 2005.

. \& GIANNOTTI, M. A. "Mapas na Web". Revista do Departamento de Geografia, Volume Especial RDG 30 anos, 2012, pp. 171-189.

QUEIROZ NETO, J. P. de. "Geomorfologia e Pedologia". Revista Brasileira de Geomorfologia, vol. 1, n. 1,2000 .

QUEIROZ NETO, J. P. de. "Pedologia: Conceito, Método e Aplicações". Revista do Departamento de Geografia, vol. 3, 1984, p. 95-110.

ROSS, J. L. S. "Análise e Síntese na Abordagem Geográfica da Pesquisa para o Planejamento Ambiental". Revista do Departamento de Geografia, vol. 9, 1995, pp. 65-75.

SANTOS, A. M. F. dos. "(Web)cartografia e Realidade Aumentada: Novos Caminhos para o Uso das Tecnologias Digitais no Ensino de Geografia". Geosaberes - Revista de Estudos Geoeducacionais, vol. 9, n. 17, dez. 2017, pp. 1-14.

SILVA, F. G. \& CARNEIRO, C. D. R. "Geotecnologias como Recurso Didático no Ensino de Geografia: Experiência com o Google Earth". Caminhos de Geografia, vol. 13, n. 41, 2012.

SOUSA, H. F T. de \& MATOS, F. S. "O Ensino dos Solos no Ensino Médio: Desafios e Possibilidades na Perspectiva dos Docentes". Geosaberes - Revista de Estudos Geoeducacionais, vol. 3, n. 6, 2012, pp. 71-78.

UNIVERSIDADE DE SÃO PAULO. Sistema Júpiter - Grade Curricular do Bacharel em Geografia - Disciplina FLG 1254 - Pedologia. Disponível em: $<$ https://uspdigital.usp.br/jupiterweb/obterDisciplina?sgldis $=$ FLG1254\&codcur $=8021 \&$ codhab $=104>$. Acessado em 20 maio 2018.

UNIVERSIDADE FEDERAL DE MATO GROSSO. Resolução Consepe N. 80, de 27 de Abril de 2009. Fundamentos de Geomorfologia. Disponível em: <http://sistemas.ufmt.br/ufmt.resolucao/files/2009/ csp/80.doc $>$. Acessado em 20 maio 2018.

UNIVERSIDADE FEDERAL DE PERNAMBUCO. Grade Gurricular do Bacharel em Geografia Disciplina CG 214 - Pedologia. Disponível em: \https:// www.ufpe.br/documents/38970/411209/geografia_bacharelado_2102.pdf/7875aa0b-81bb-4549-bd20-d5b1662d3bac >. Acessado em 20 maio 2018. 
UNIVERSIDADE FEDERAL DO PARANÁ. Grade Curricular do Bacharel em Geografia - Disciplina GB 100 - Pedologia. Disponível em: <http://www. geografia.ufpr.br/portal/wp-content/uploads/2013/04/ Ementas-das-Disciplinas-do-Curso-de-Geografia_atualizada2.pd† $>$. Acessado em 20 maio 2018.

UNIVERSIDADE FEDERAL DO RIO GRANDE DO SUL. Grade Curricular do Bacharel em Geografia - Disciplina GEO 01025 - Introdução à Pedologia e Ecogeografia. Disponível em: <http:// www.ufrgs.br/ufrgs/ensino/graduacao/cursos/exibeCurso?cod_curso=331>. Acessado em 20 maio 2018.

VAN ES, H. "A New Definition of Soil". CSANews, 2017, pp. 20-21.

Publicado em 04/07/2018. 